\title{
EMPLOYEE INVOLUNTARY TURNOVER COSTS IN TOURISM INDUSTRY: A LOOK FROM 5-STAR HOTELS IN ANTALYA REGION OF TURKEY
}

\begin{abstract}
Akın Aksu ${ }^{1}$
Abstract:Turnover has special importance in the hospitality industry. The main importance of employee turnover comes from its negative economical effects on establishments. Employee turnover rates are high, in both the private sector and the govermental sector. It is not easy to find validated and updated information on this subject for Antalya. Neither cost components nor costs of personnel turnover have been investigated in detail. The calculations show that with increases in qualification and experience, the costs of turnover increase. For 2016, the turnover costs for a housekeeper are between 2,179 US\$ and 5,475 US\$, between 2,009 US\$ and 7,221 US\$ for a reservation chief, between 8,283 US\$ and 29,996 US\$ for a food \& beverage manager, and between 11,555 US\$ and 24,391 US\$ for a front office manager. Hotels must be careful, especially regarding involuntary turnover, because this generally serves as a red flag to employees and potential applicants. Hotels with consistently high involuntary turnover rates could have serious problems recruiting new employees in the future.
\end{abstract}

Keywords:Employee involuntary turnover, tourism industry, 5-Star Hotels, Antalya

\section{The Importance, Effects and Process of Employee Turnover}

Employee turnover can be seen as one of the indicators of the touristic establishment's working conditions.Because of high employee-customer interaction, turnover has special importance in the hospitality industry. In literature it is possible to see a number of publications regarding turnover motives (Robinson, 2005, p. 349). There are two types of employee turnover: (1) voluntary and (2) involuntary. In voluntary turnover employees leave establishments based on free choice and in involuntary turnover establishments give the decision of seperate.

Possible reasons for voluntary turnover are low salary, job dissatisfaction for the people with high expectancy levels, bad relations with superiors and colleagues, lack of job security, educational purposes for students, family purposes especially for females, better job opportunity purposes, experiencing new jobs and alternative job offers especially for skilled employee, etc. Voluntary turnover affects organizational

\footnotetext{
${ }^{1}$ Professor, Akdeniz University Faculty of Tourism, Antalya, aaksu@akdeniz.edu.tr
} 
effectiveness in reaching their goals. Therefore managers must be aware of the situation and must give support for minimizing the cost of unwanted separations (Price, 2001, p. 601). In involuntary turnover, the establishments remove employees(examples: poor performance, economic conditions, etc.).

According to the related literature employee turnover (voluntary or involuntary) can be seen as a physical seperation and most of the studies investigated demographic aspects as important actors in turnover process (Mobley, 1982, p.111). Morrell and et al (2004) classified turnover studies in two groups; 1) Labour-market school and 2) Psyclogical school studies.Labour-market school studies are mainly concentrated on external variables (like job alternatives, performance) affecting turnover and assume that all employees are homogeneous. With different perspective, psyclogical school studies are focused on explaining of employees' behaviours (like job satisfaction, organizational commitment).

In practice, possible employee turnover process starts with recruitment of new employees. The first day at job is always important for the new employees. Possibly wrong candidate was accepted for the job and he / she will not be successful in the near future. In order to avoid these circumstances recruiting right employees according to job descriptions and expectations of establishments are important (The Educational Institute, 1984). For right recruitment decisions referrals of present employees can be also thought. Since present employees know the current working conditions and expectations of their managements, they can help to potential employees in translating the realities about the establishment. If managements confirm referrals of present employees, with this way there is a possibility of decreasing the number of wrong applications (Linnehan and Blau, 2003, p.256).

Regarding turnover, interview process alone plays an important role in right or wrong decisions for new employees.For the wrong decision cases the common aspects are;

*Defining the individual characateristics in a wrong way, *Having time limitation for selecting the right employee, *Not giving enough time and interest to recruitment process.

After recruiting the right employee for the job, in some cases possible turnover can be thought again cause of his/her bad impression for the establishment. The impression and feeling of new employees starting from first day to last day in the establishment will define stay or leave decision.Beside recruitment, "opportunity" is one of main determinant of turnover. Here "opportunity" means the availability of alternative jobs in surrounding. If the employee perceives alternative job is better 
than his / her current job, then he / she can quit from the establishment (Price, 2001,p.601). Related with job, but from other perspective giving the first job to new employee is important and affect employee directly.Giving first job after a reasonable orientation period can be done.The first job must be easy to do and new employee must be ready for the first job.In order to reach this aim; on the job training, in-house training or orientation programmes can be suggested. Nowadays many organizations are trying to improve their current orientation programmes. A successful orientation programme must be updated, written and have standarts according to the rules of the establishments and status of new employees.Together with establishment presentations, a manuel (showing vision, mission and important values of establishment) must be given. During and just after orientation periods possibly bad impressions can be occur and affect stay or leave decision of employees.Carefully organized orientation programmes enable 2 positive developments in the organizations; 1)turnover rates of new employees decreases and 2)the number of stayers in the establishment increases. Figure 1, the study of Werther and Davis (1996), shows effects of short and long-term orientation programmes on turover rates.

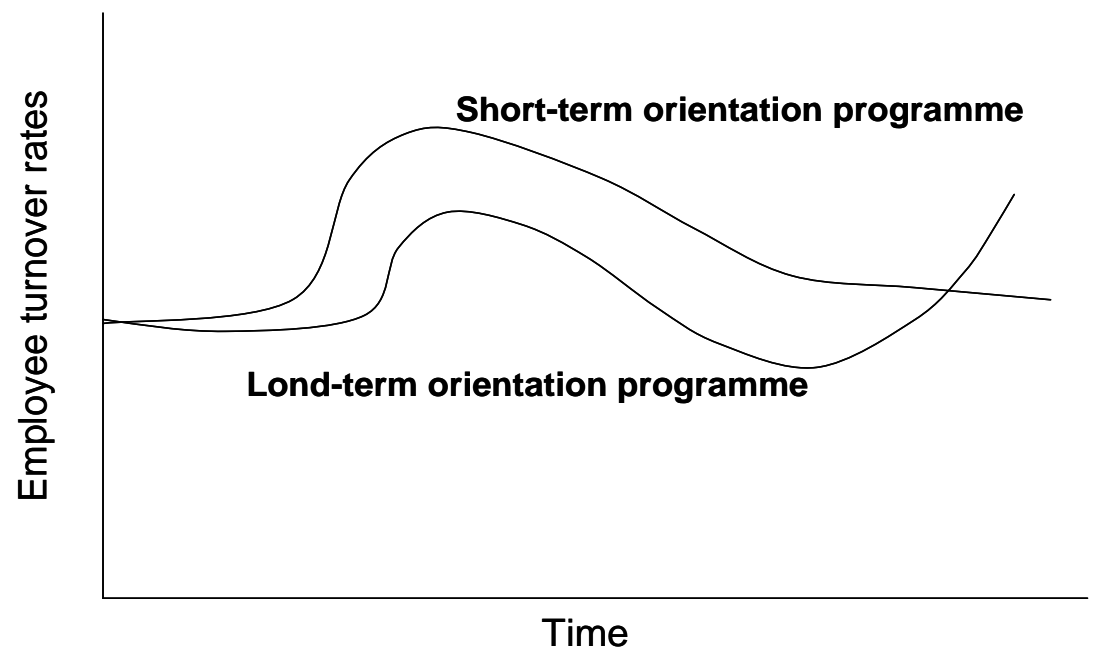

Figure 1: Effects of Short and Long Term Orientation Programmes on Turnover Rates

Source: Werther and Davis (1996)

Employee turnover can be seen as a final step of job / establishment dissatisfaction. If an employee has dissatisfaction he / she will have 3 possible steps; 
1)He / she will go on obeying the rules and norms of the establishment, 2) $\mathrm{He} /$ she leaves the establishment,

3)He / she limits his / her performance (İncir, 1989,p.50).

Robbins (1993) found that individuals show their dissatisfaction in different ways, as shown in figure 2 ;

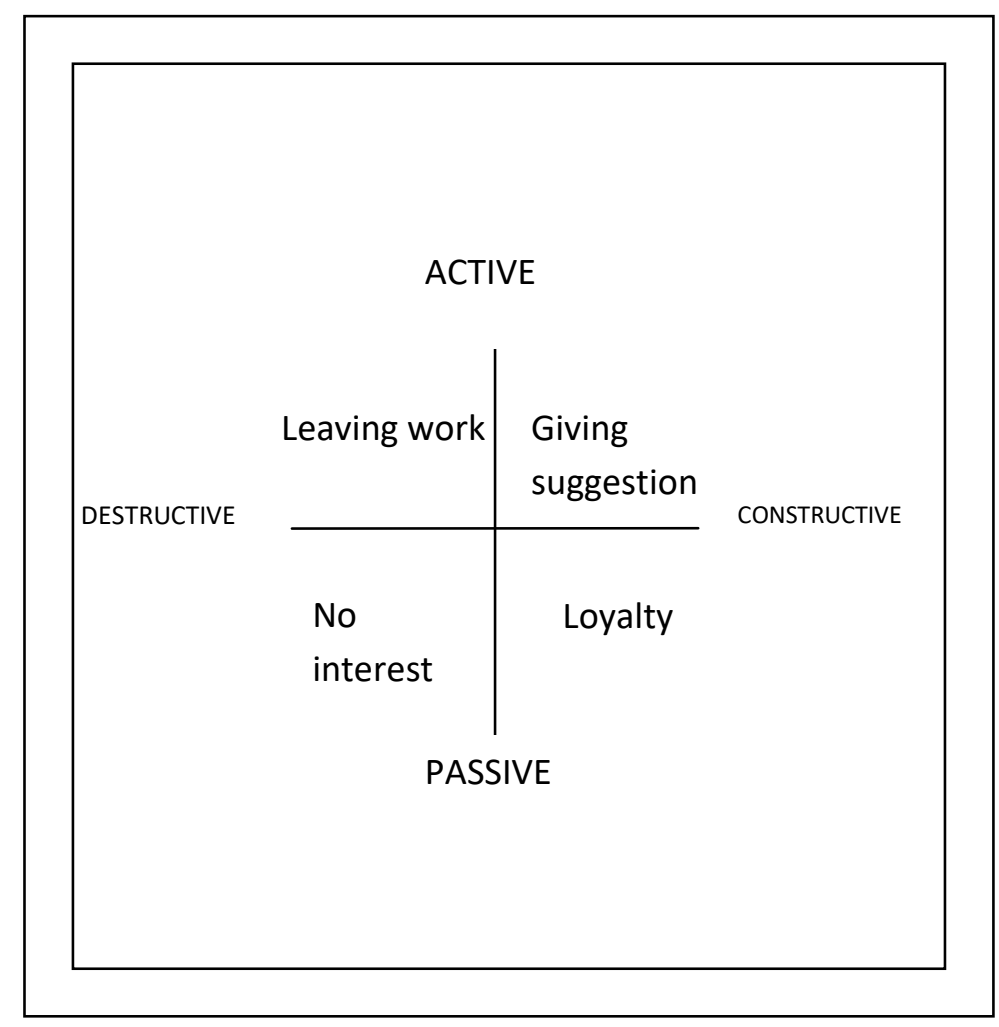

Figure 2: Different Ways of Showing Dissatisfaction Source: Robbins (1993)

Leaving work: Means leaving of work and establishment at the same time.

Giving Suggestion: Means suggestions coming from the employee in order to improve working conditions.

Loyalty: Means waiting of employee in a passive way for having an improvement in working conditions.

No interest: Waching the negative developments in the establishment in a passive way.In this situation there will be continuous absenteism and work 
accidents.Employee turnover in a way means, aggreement of employees and employers.There must be idea of maintaining employment relation (Dalton and et al, 1982,p.118).Both sides must have the decision of stay in order to continue their partnerships.

In the hospitality industry employee turnover is generally high by comparison with other industries. According to Horton and Ghiselli (1999) there are 30 different individual factors affecting turnover (Walmsley, 2004,p. 276). Working hours, work stress, working conditions, seasonality problems, outsourcing, personal problems, existence of alternative works, poor performance, economical problems and many other factors may easily affect turnover. The main importance of employee turnover comes from its negative economical effects on establishments.Drummond (1990) reports that turnover costs can go up to $\$ 2000$ $\$ 3000$ for skilled employee such as line cooks and servers. Even for the minimum wages, the replacement cost of a new employee will be approximately $\$ 3700$ (Lim $\&$ Boger, 2005, p. 62). Especially high turnover increases employment costs. Here for employee costs,separation costs of terminated employees, replacement costs and training costs and productivity loss ofnew employees during new employee orientation period must be considered.

\section{Calculation of Employee Turnover Costs}

There are three main components according to Cascio (1995, pp. 582, 583);

\section{Separation costs}

\section{Replacement costs}

\section{Training costs}

The sum of these three cost components represents the total turnover costs.

\section{Separation costs:}

\section{Exit interview}

2.Administrative functions related to termination (example removal of the employee from the payroll, termination of benefits, etc.) 
3.Separation pay

\section{Replacement costs:}

1. Communicating job availability

2. Preemployment administrative functions (accepting applications and checking references)

3. Entrance interview

4. Testing and/or other types of assessment procedures

5. Employee meetings

6. Travel and moving expenses (travel for all applicants and travel plus moving expenses for all new hires)

7. Postemployment acquisition and dissemination of information (all the activities associated with in-processing new employee)

8. Medical examinations

\section{Training costs (orientation):}

1.Formal training programme / on-the-job training

2.Productivity loss

\section{Employee Involuntary Turnover Costs in 5-Star Hotels in Antalya}

Employee turnover rates are high, in both the private sector and the govermental sector. It is not easy to find validated and updated information on this subject for Antalya. Neither cost components nor costs of personnel turnover have been investigated in detail. In order to calculate involuntary costs, some assumptions must be set. In this study different positions were selected just as examples: 1) a housekeeper with 2 years of experience, 2) a reservation chief with 1 year of experience, and 3) a food \& beverage manager with 3 years of experience, 4) Front 
Office Manager with 5 years' experience; 5) Accounting Clerk with 1 year of experience; 6) kitchen staff with 3 years' experience and 7) Technical Services Manager with 4 years' experience. These seven positions were selected as examples. Responses were received for these different positions from different hotels sampled. Of course the cost of personnel turnover for other positions in a hotel can also be calculated.

All calculations were based on the replies of the human resources managers. To determine real costs, the gross monthly wages of personnel were divided by 30 to find the daily figures. Then the daily amounts were divided by 450(7.5 hours X 60 minutes) to find the wages perminute. For the hotels sampled, the average work day was assumed to be 7.5 hours (although in the hospitality industry many employees work more than 7.5 hours per day). First, all calculations were made in Turkish lira and then converted to US dollars to be consistent with the literature and to make comparisons easier for international readers. When converting the calculations, the currency rates of the Turkish Central Bank were used. In all calculations Cascio's costs of turnover componentswere used, but they were revised for Turkey's conditions and applications. For example, in Turkey there are two legal separation payments:1) severance pay and 2) leave compensation. For severance pay personnel must have worked a minimum of 1 year, and there is a maximum amount tobe paid in a year. This amount is set twice a year by the Turkish government, for example in the year 2000 it was $\$ 841$. For leave compensation, payment can be made in two ways: 1) paying terminated personnel according to his/her work experience, or 2) giving leave toterminated personnel according to his/her work experience. For work experience this leave is calculated

according to the government standards as follows: 14 days off for work experience of less than 6 months; 28 days off for work experience of 6 months to 1.5 years; 42 days off for work experience of 1.5 to 3 years; 56 days off for work experience of 3 years and more. All hotels sampled declared that they prefer to pay for terminated personnel.With this regard starting from 2000 till 2016, it was possible to calculate Employee Involuntary Turnover Costs in 5-Star Hotels in Antalya (Aksu et al., 2016, pp.168-179).

The calculations show that with increases in qualification and experience, the costs of turnover increase. For 2016, the turnover costs for a housekeeper are between 2,179 US\$ and 5,475 US\$, between 2,009 US\$ and 7,221 US\$ for a reservation chief, between 8,283 US\$ and 29,996 US\$ for a food \& beverage manager, and between 11,555 US\$ and 24,391 US\$ for a front office manager. For 2000, 2010 and 2016, the cost of involuntary turnover for a housekeeper, the only common position in all three years, increased from a minimum of 721 US\$ in 2000 
to a maximum of 5,475 US\$ in 2016. The turnover costs for the hotels in the sample varied due to their differing wage and human resource policies and procedures.

\section{Conclusions and Suggestions for Decreasing Employee Involuntary Turnover}

*By years, there were no differences among the hotels in terms of looking for staff, wages, and importance of personnel. However, hotels must be careful, especially regarding involuntary turnover, because this generally serves as a red flag to employees and potential applicants. Hotels with consistently high involuntary turnover rates could have serious problems recruiting new employees in the future.

*One of the realities of the hospitality industry is that it does not always offer attractive and continous working conditions. In this context, hoteliers must know these situations and improve working conditions of their employees and give enough importance to career planning of employees in order to increase their service quality.

*This research provides a focus on the "soft calculation" of involuntary turnover costs.

Normally it would be better to also determine the financial effects of decreases in morale and motivation of employees.

*Hotels should have both internal and external positive images. High turnover rates will damage these positive images. It is well known that "word-of-mouth publicity" is widely used in the tourism sector worldwide. The positive image or negative image of a hotel can be the subject of customers (external) and personnel (internal). Hoteliers in Antalya don't face problems in finding new employees, but in the future they may have problems because of their bad images among labors.

*Maintaining competitive pay scales may increase performance of employees.This can benefit both the organization and the employees (i.e., by decreasing turnover and maintaining continuous work performance by qualified personnel, and by maintaining employee morale and motivation with adequate financial compensation). 


\section{REFERENCES}

Aksu, et al., (2016). Calculating the Cost of Turnover at 5-Star Hotels in Turkey between 2000 and 2016, Turizam, 20 (4), 168-179.

Cascio, W. F. (1995). Managing human resources productivity, quality of worklife, profits (4th ed.). New York: Mc Graw-Hill, Inc.

Dalton, D. R. and et al.(1982). Turnover overstated: the functional taxonomy. The Academy of Management Review, 7 (1), 117-123.

Drummond, K. E. (1990). Human resource management for the hospitality industry. New York: Van Nostrand Reinhold.

Horton, B. W., \& Ghiselli, R. (1999). Identification of variables influencing food and beverage employee turnover. In: K. S. Chon (Ed.), In the practice of graduate research in hospitality and tourism. New York: Haworth Hospitality Press.

İncir, G. Çalışanların örgütsel gereksinimleri ve iş doyumu.Paper presented at the 1989 2.Ulusal Ergonomi Kongresi MPM.Ankara.

Lim, E., \& Boger, E. (2005). Management requires leadership.Consortium Journal of Hospitality and Tourism, 9(1), 59-66.

Linnehan, F. and Blau, G.(2003). Testing the impact of job search and recruitment source on new hire turnover in a Maquiladora. Applied Psychology: An International Review, 52 (2), 253-271.

Mobley, W.H.(1982). Some unanswered questions in turnover and withdrawal research. Academy of Management Review, 7 (1), 111-116.

Morrell, K. and et al.(2004).The role of shocks in employee turnover. British Journal of Management, 15, 335-349.

Price, J. L. (2001). Reflections on the determinants of voluntary turnover. International Journal of Manpower, 22(7), 600-624

Robinson, R. N. S. (2005). Tradeperson or artist? A critical exploration of chefs' job satisfaction and turnover. Tourism, 53(4), 347-355 
Robbins, S.(1993).Organizational behavior. New Jersey: Prentice-Hall Inc Englewood Cliffs.

The Educational Institute.(1984). Reducing employee turnover. Michigan: First Edition.

Walmsley, A. (2004). Assessing staff turnover: A view from the English Riviera. International Journal of Tourism Research, 6, 275-287.

Werther, W.B. and Davis, JR.K.(1996). Human resources and personel management. Singapore: Mc Graw-Hill, Third Edition. 